\title{
Kinetics and Mechanism of the Change of the 4-Nitrobenzylthio-System into 4,4'-Diformylazoxybenzene in Alkaline Dioxane-Water Media
}

\author{
Y. Riad, Adel N. Asaad, G.-A. S. Gohar, and A. A. Abdallah \\ Department of Chemistry, Faculty of Science, Alexandria University, Alexandria, Egypt \\ Z. Naturforsch. 40 a, $1128-1132$ (1985); received November 29, 1984
}

\begin{abstract}
Sodium hydroxide reacts with $\alpha$-(4-nitrobenzylthio)-acetic acid in aqueous-dioxane media to give $4,4^{\prime}$-diformylazoxybenzene as the main product besides $4,4^{\prime}$-dicarboxyazoxybenzene and a nitrone acid. This reaction was kinetically studied in presence of excess of alkali in different dioxane-water media at different temperatures. It started by a fast reversible $\alpha$-proton abstraction step followed by two consecutive irreversible first-order steps forming two intermediates ( $\alpha$-hydroxy, 4-nitrosobenzylthio)-acetic acid and 4-nitrosobenzaldehyde. The latter underwent a Cannizzaro's reaction, the products of which changed in the reaction medium into $4,4^{\prime}$-diformylazoxybenzene and 4,4'-dicarboxyazoxybenzene. The rate constants and the thermodynamic parameters of the two consecutive steps were calculated and discussed. A mechanism was put forward for the formation of the nitrone acid.

Other six 4-nitrobenzyl, aryl sulphides were qualitatively studied and they gave mainly $4,4^{\prime}$-diformylazoxybenzene beside 4,4'-dicarboxyazoxybenzene or its corresponding azo acid.
\end{abstract}

\section{Introduction}

The preparation of azoxy- and azo-compounds directly from nitro aromatics under mildly reducing conditions has for long being attractive for chemists $[1-7]$.

The present report is a kinetic study of the action of alkali on $\alpha$-(4-nitrobenzylthio)-acetic acid (I), and the like, in order to reach a factual mechanism for its transformation into 4,4-diformyazoxybenzene.

\section{Experimental}

Action of alkali on $x$-(4-nitrohenzythio)-acetic acid $[8,9]$

\section{a) In $50 \%$ aqueous dioxane}

The acid $(3 \mathrm{~g})$ was dissolved in $25 \mathrm{ml}$ dioxane and $25 \mathrm{ml} 10 \%$ aqueous sodium hydroxide. Boiling for one minute, cooling, dilution and filteration gave a solid $(1.27 \mathrm{~g})$ that crystallized from benzene, m.p. $190^{\circ}$ undepressed when mixed with an authentic specimen of 4,4'-diformylazoxybenzene. Acidification of the Alkaline filtrate evolved hydrogen sul-

Reprint requests to Herrn Dr. A. N. Asaad, Institut für Physikalische Chemie und Elektrochemie, Lehrstuhl III, University Karlsruhe, Kaiserstraße 12, D-7500 Karlsruhe. phide and gave a precipitate $(0.53 \mathrm{~g})$, which was a mixture of two acids, one soluble in boiling ethanol $(0.37 \mathrm{~g})$ while the insoluble part was $(0.16 \mathrm{~g})$.

(i) The soluble part in boiling ethanol decomposed at $360^{\circ}$ and was identified as a nitrone having a molecular formula $\mathrm{C}_{18} \mathrm{H}_{16} \mathrm{~N}_{2} \mathrm{O}_{8} \mathrm{~S}_{2}$ (452): requires: $\mathrm{N}, 6.2 \%$; found $\mathrm{N}, 6.2 \%$. Its molecular weight according to Rast's method [10] was found to be $450 \pm 3$. IR ( $\mathrm{KBr}$ disk): 1600 (aromatic rings), $1580(\mathrm{C}=\mathrm{N})[11,12]$ and $1280 \mathrm{Cm}^{-1}(\mathrm{~N} \rightarrow \mathrm{O})[13]$; $\mathrm{UV} 1 \times 10^{-4}$ in $2 \times 10^{-4} \mathrm{M} \mathrm{NaOH}(50 \%$ aq. dioxane) $i_{\max }=340 \mathrm{~nm} \log \varepsilon=4.5\left(\pi-\pi^{*}\right.$ transition $)[11,13$, 14]; ${ }^{1} \mathrm{H}-\mathrm{NMR}$ (DMSO): $\delta=1.2\left(\mathrm{~s}, 4 \mathrm{H}, 2 \mathrm{CH}_{2}\right), 1.85$ $(\mathrm{s}, 2 \mathrm{H}, \mathrm{CHOH}), 7.4-8.4(\mathrm{~m}, 8 \mathrm{H}$, aromatic) and 10.15 (s, $2 \mathrm{H}$, acidic).

(ii) The insoluble acid in boiling ethanol was crystallized from dilute acetic acid, did not melt up till $360^{\circ}$ was identified as $4,4^{\prime}$-dicarboxyazoxybenzene [5]. $\mathrm{C}_{14} \mathrm{H}_{10} \mathrm{~N}_{2} \mathrm{O}_{5}$ requires: $\mathrm{C}, 58.7 ; \mathrm{H}, 3.5$; N, 9.8\%. Found: C, 58.9; H, 4.0; N, 9.67\%. IR ( $\mathrm{KBr}$ disk $): 3100-2550(\mathrm{OH}), 1698(\mathrm{C}=\mathrm{O}), 1425(\mathrm{~N}=\mathrm{N})$ [15] and $1290 \mathrm{Cm}^{-1}(\mathrm{~N} \rightarrow \mathrm{O})$ [15]. UV $1 \times 10^{-4}$ in $2 \times 10^{-4} \mathrm{M} \mathrm{NaOH}\left(50 \%\right.$ aq. dioxane) $\lambda_{\max }=334 \mathrm{~nm}$ $\log \varepsilon=4.3$. ${ }^{1} \mathrm{H}-\mathrm{NMR}$ (DMSO): $\delta=7.9-8.5(\mathrm{~m}, 8 \mathrm{H}$, aromatic) and 10.15 (d, $2 \mathrm{H}$, acidic).

b) In deuterium oxide medium

I $(1.5 \mathrm{~g})$ was dissolved in $25 \mathrm{ml}$ of a $5 \%$ solution of sodium hydroxide in deuterium oxide, and left at 
room temperature for $30 \mathrm{~min}$. The reaction was interrupted by acidification, the unreacted acid was recovered, crystallized from dilute ethanol and its ${ }^{1} \mathrm{H}-\mathrm{NMR}$ (DMSO) spectrum was compared with that of pure starting acid. For I $\delta=3.15(\mathrm{~s}, 2 \mathrm{H}$, $-\mathrm{CH}_{2} \mathrm{COO}^{-}$), 3.95 (s, $2 \mathrm{H}$, benzylic) while for the recovered acid there was about $15 \%$ decrease in the intensity of the signal corresponding to the benzylic hydrogens, which meant that $H / D$ exchange took place.

Action of sodium methoxide on $\boldsymbol{I}$ in absolute methanol

The acid $(0.58 \mathrm{~g})$ was dissolved in dry methanol $(25 \mathrm{ml})$, treated with $0.2 \mathrm{~N}$ sodium methoxide $(25 \mathrm{ml})$. The mixture was refluxed for $24 \mathrm{~h}$. No reaction took place. Acidification and dilution precipitated the starting acid.

\section{Action of sodium hydroxide on 4-nitrosobenzaldehyde} [16]

The reaction did not give the expected products, namely, 4-nitrosobenzyl alcohol and 4-nitrosobenzoic acid, but gave equimolecular quantities of $4,4^{\prime}$-diformylazoxybenzene and 4,4'-dicarboxyazoxybenzene.

Action of sodium hydroxide on some 4-nitrobenzyl, aryl sulphides

Each of the following compounds was treated with sodium hydroxide in $50 \%$ aqueous dioxane medium in a similar way to $\mathbf{I}$. The reactions products are given in Table 1 .

The procedure used to purify the 1,4-dioxane has been described elsewhere [17].

\section{Kinetic procedure}

The reaction of $\mathbf{I}$ and sodium hydroxide was followed by measuring the ultraviolet-visible absorption of the reaction at $420 \mathrm{~nm}$ using a Unicam 1805 SP spectrophotometer coupled with an ultrathermostate. One $\mathrm{ml}$ of each of the reactant solutions, I $\left(2 \times 10^{-3} \mathrm{M}\right.$ in appropriate dioxanewater mixture) and sodium hydroxide $\left(2 \times 10^{-1} \mathrm{M}\right.$ in water) were separately introduced into the two parts of the two compartment cell whose thickness was $0.437 \mathrm{Cm}$ (Hellma, 238-QS) and thermostated for $15 \mathrm{~min}$. After shaking the cell contents, 5-10 s, the absorption of the reaction mixture was recorded at suitable time intervals.

\section{Results and Calculations}

The reaction of aqueous sodium hydroxide on $\mathbf{I}$ was found to give, besides the already known 4,4'diformylazoxybenzene $(73.3 \%)$, two other acids, namely, 4,4'-dicarboxyazoxybenzene $(8.41 \%)$ and a nitrone acid (IV) (12.74\%).

The reaction was studied kinetically in different aqueous-dioxane media containing 5, 10, 20, 30, 40, and $50 \%(\mathrm{v} / \mathrm{v})$ dioxane at $35,45,55$ and $65^{\circ}$. The

Table 1. Products of the action of sodium hydroxide on some 4-nitrobenzyl, aryl sulphide in aqueous or in $50 \%$ aqueous dioxane.

\begin{tabular}{|c|c|c|}
\hline Aryl group & $\begin{array}{l}\text { Percipitate after heating } \\
\text { and dilution }\end{array}$ & $\begin{array}{l}\text { Material set free } \\
\text { after acidification }\end{array}$ \\
\hline phenyl [18] & 4,4'-diformylazoxybenzene & $\begin{array}{l}\text { thiophenol and } \\
4,4^{\prime} \text {-dicarboxyazobenzene }\end{array}$ \\
\hline 4-methyl phenyl & $4,4^{\prime}$-diformylazoxybenzene & $\begin{array}{l}\text { 4-methyl thiophenol } \\
\text { and } 4,4^{\prime} \text {-dicarboxyazo- } \\
\text { benzene }\end{array}$ \\
\hline 2-carboxy phenyl [20] & $4,4^{\prime}$-diformylazoxybenzene & $\begin{array}{l}\text { disulphide of } \\
\text { 2-thiolbenzoic acid [21] }\end{array}$ \\
\hline 4-methoxy phenyl [19] & $4,4^{\prime}$-diformylazoxybenzene & $\begin{array}{l}\text { 4-methoxy thiophenol } \\
\text { and } 4,4^{\prime} \text {-dicarboxyazoxy- } \\
\text { benzene }\end{array}$ \\
\hline 4-chloro phenyl [19] & $4,4^{\prime}$-diformylazoxybenzene & $\begin{array}{l}\text { 4-chloro thiophenol and } \\
4,4^{\prime} \text {-dicarboxyazoxybenzene }\end{array}$ \\
\hline 4-nitrobenzyl [22] & $4,4^{\prime}$-diformylazoxybenzene & $\begin{array}{l}\text { disulphide of } \\
\text { 4-nitrobenzylthiol [23] }\end{array}$ \\
\hline
\end{tabular}


Table 2. Rate constants $k_{1}$ and $k_{2}$ for the consecutive reaction between sodium hydroxide and $\alpha$-(4-nitrobenzylthio)acetic acid in dioxane-water mixtures.

\begin{tabular}{|c|c|c|c|c|c|c|}
\hline \multirow[t]{2}{*}{$t\left[{ }^{\circ} \mathrm{C}\right]$} & \multirow{2}{*}{$\begin{array}{l}k \cdot 10^{4} \\
{\left[\mathrm{~s}^{-1}\right]}\end{array}$} & \multicolumn{5}{|c|}{ dioxane [vol \%] } \\
\hline & & 10 & 20 & 30 & 40 & 50 \\
\hline 35 & $\begin{array}{l}k_{1} \\
k_{2}\end{array}$ & $\begin{array}{r}2.47 \\
\pm 0.14 \\
0.90 \\
\pm 0.05\end{array}$ & $\begin{array}{r}3.28 \\
\pm 0.29 \\
1.07 \\
\pm 0.08\end{array}$ & $\begin{array}{r}1.81 \\
\pm 0.13 \\
2.65 \\
\pm 0.28\end{array}$ & $\begin{array}{r}1.81 \\
\pm 0.15 \\
2.33 \\
\pm 0.24\end{array}$ & $\begin{array}{r}1.45 \\
\pm 0.08 \\
1.91 \\
\pm 0.15\end{array}$ \\
\hline 45 & $\begin{array}{l}k_{1} \\
k_{2}\end{array}$ & $\begin{array}{r}6.76 \\
\pm 1.24 \\
1.87 \\
\pm 0.39\end{array}$ & $\begin{array}{r}5.97 \\
\pm 0.28 \\
2.42 \\
\pm 0.11\end{array}$ & $\begin{array}{r}3.78 \\
\pm 0.21 \\
8.47 \\
\pm 0.73\end{array}$ & $\begin{array}{r}3.54 \\
\pm 0.21 \\
6.44 \\
\pm 0.58\end{array}$ & $\begin{array}{r}2.41 \\
\pm 0.16 \\
2.69 \\
\pm 0.21\end{array}$ \\
\hline 55 & $\begin{array}{l}k_{1} \\
k_{2}\end{array}$ & $\begin{array}{r}12.19 \\
\pm 0.94 \\
3.48 \\
\pm 0.31\end{array}$ & $\begin{array}{r}12.71 \\
\pm 1.25 \\
5.61 \\
\pm 0.54\end{array}$ & $\begin{array}{r}9.05 \\
\pm 0.12 \\
12.06 \\
\pm 0.22\end{array}$ & $\begin{array}{r}7.92 \\
\pm 0.37 \\
9.00 \\
\pm 0.61\end{array}$ & $\begin{array}{r}5.82 \\
\pm 0.51 \\
3.71 \\
\pm 0.30\end{array}$ \\
\hline 65 & $\begin{array}{l}k_{1} \\
k_{2}\end{array}$ & $\begin{array}{l}- \\
-\end{array}$ & $\begin{array}{r}18.60 \\
\pm 0.82 \\
7.05 \\
\pm 0.29\end{array}$ & $\begin{array}{r}20.28 \\
\pm 2.78 \\
14.02 \\
\pm 1.80\end{array}$ & $\begin{array}{r}17.42 \\
\pm 2.59 \\
11.03 \\
\pm 1.44\end{array}$ & $\begin{array}{r}9.10 \\
\pm 0.21 \\
5.56 \\
\pm 0.61\end{array}$ \\
\hline
\end{tabular}

Table 3 . Thermodynamic parameters of activation at $35^{\circ} \mathrm{C}$.

\begin{tabular}{|c|c|c|c|c|c|}
\hline \multirow[t]{2}{*}{ Parameter } & \multicolumn{5}{|c|}{ dioxane [vol \%] } \\
\hline & 10 & 20 & 30 & 40 & 50 \\
\hline $\begin{array}{c}\Delta G_{1}^{\neq}\left[\mathrm{kJ} \mathrm{mol}^{-1}\right] \\
\Delta H_{1}^{\neq}\left[\mathrm{kJ} \mathrm{mol}^{-1}\right] \\
-\Delta S_{1}^{\neq}\left[\mathrm{J} \mathrm{mol}^{-1} \mathrm{deg}^{-1}\right]\end{array}$ & $\begin{array}{r}97.00 \\
34.05 \\
204.27\end{array}$ & $\begin{array}{r}96.34 \\
27.01 \\
225.09\end{array}$ & $\begin{array}{r}97.83 \\
38.82 \\
191.51\end{array}$ & $\begin{array}{r}97.85 \\
32.99 \\
210.51\end{array}$ & $\begin{array}{r}98.34 \\
28.09 \\
227.97\end{array}$ \\
\hline $\begin{array}{c}\Delta G_{2}^{\neq}\left[\mathrm{kJ} \mathrm{mol}^{-1}\right] \\
\Delta H_{2}^{\ddagger}\left[\mathrm{kJ} \mathrm{mol}^{-1}\right] \\
-\Delta S_{2}^{\neq}\left[\mathrm{J} \mathrm{mol}^{-1} \mathrm{deg}^{-1}\right]\end{array}$ & $\begin{array}{r}99.30 \\
24.66 \\
242.21\end{array}$ & $\begin{array}{r}98.79 \\
29.91 \\
223.54\end{array}$ & $\begin{array}{r}96.32 \\
23.04 \\
237.81\end{array}$ & $\begin{array}{r}96.67 \\
24.70 \\
235.51\end{array}$ & $\begin{array}{r}101.82 \\
18.95 \\
269.06\end{array}$ \\
\hline
\end{tabular}

reaction course was followed by determining the absorption at $420 \mathrm{~nm}$, at which there is no absorption by the starting acid but all the reaction products do absorb.

Although the ratio acid: alkali was 1:100, yet the kinetic results did not conform to a first-order rate equation. The reaction, by virtue of its complex nature, was considered to involve two consecutive irreversible first-order reactions of the type $\mathbf{I} \stackrel{k_{1}}{\rightarrow}$ II $\stackrel{k_{2}}{\rightarrow}$ III, where I, II and III represent starting material, intermediate and 4-nitrosobenzaldehyde, respectively, and $k_{1}$ and $k_{2}$ represent the rate constants of these two steps. III undergoes a Cannizzaro's disproportionation exhibiting third-order kinetics, second order in aldehyde and first order in base [16]. To calculate the rate constants from a set of experimental data, the time ratio method, developed by Swain [24] and then by Frost and Schwemer [25]. was used. The steady state approximation treatment was applied to the intermediate II. The values of $k_{1}$ and $k_{2}$ are collected in Table 2 at the indicated temperatures.

The calculated thermodynamic parameters of activation [26], $\Delta H^{\ddagger}, \Delta G^{\ddagger}$ and $\Delta S^{\ddagger}$ are collected in Table 3.

\section{Discussion}

In 1951 Iskander and Riad [8] reported a schematic mechanism for the action of aqueous sodium hydroxide on I, where 4-nitrosobenzyl alcohol or ( $\alpha$-hydroxy, 4-nitrosobenzylthio)-acetic acid (II) was expected to be formed according to either C-S fission or aci-formation taking the lead.

In the present work it was proved that $\mathbf{I}$ reacted with aqueous sodium hydroxide via a fast and reversible $\alpha$-proton abstraction step as indicated by H/D exchange. A similar $\alpha$-proton abstraction was reported to take place in 4-nitrobenzyl-halides [27], pyridinium salts [28], and sulphides [28] under similar conditions.

When I was boiled under reflux for a long time with sodium methoxide in anhydrous methanol, no reaction took place. Water is therefore essential for the reaction to give the intermediate II.

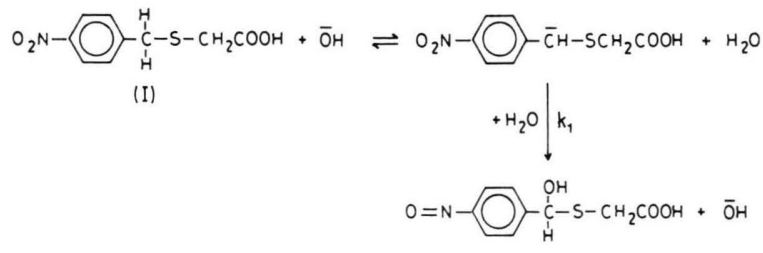

(II)

The same observation was noticed when 4-nitrophenyl acetic acid was boiled with sodium methoxide in anhydrous methanol, whereby no reaction took place, while in presence of water $\alpha$-hydroxy, 4-nitrosophenyl acetic acid was postulated to be formed [6]. Values of $k_{1}\left(\mathrm{~s}^{-1}\right)$ for this step under different conditions are compiled in Table 2.

II undergoes a base promoted elimination reaction displacing $-\mathrm{SCH}_{2} \mathrm{COOH}$ and giving rise to 4-nitrosobenzaldehyde.

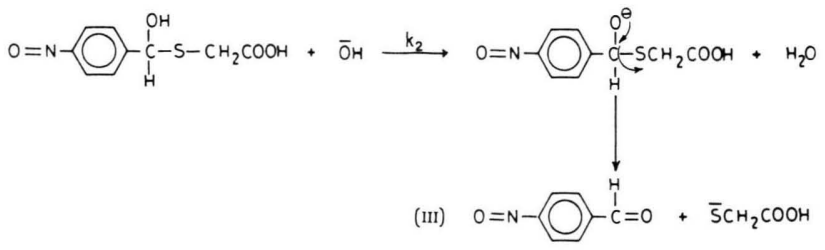


Values of $k_{2}\left(\mathrm{~s}^{-1}\right)$ for this step under different conditions are compiled in Table 2.

4-Nitrosobenzaldehyde, being soluble in aqueous dioxane in the presence of alkali, undergoes a Cannizzaro's disproportionation reaction to give rise to 4-nitrosobenzyl alcohol and 4-nitrosobenzoic acid. The latter acid is known to change in an alkaline medium very rapidly into $4,4^{\prime}$-dicarboxyazoxybenzene [16].

The kinetic behaviour of 4-nitrosobenzaldehyde with sodium hydroxide in aqueous-dioxane media under similar conditions as of the present investigation was found to exhibit third-order kinetics, not involving free-radicals, radical anions or radical chain mechanism [16]. The values of $k_{3}\left(1^{2} \mathrm{~mol}^{-2} \mathrm{~s}^{-1}\right)$ [16] are greater than those of $k_{1}$ and $k_{2}$ under the same conditions, meaning that the Cannizzaro's step is not rate determining in the present reaction.

4-Nitrobenzyl alcohol, formed via Cannizzaro's reaction, changes rapidly in the alkaline medium into 4-hydroxylaminobenzaldehyde, and this may either dimerise [29] or react with 4-nitrosobenzaldehyde to form 4,4'-diformylazoxybenzene [16]. The nitrone acid, isolated from the reaction between I and sodium hydroxide, is expected to be formed from the interaction between the anion of $\mathbf{I}$ and the intermediate II in the presence of alkali, thus affording evidence for the existence of II.

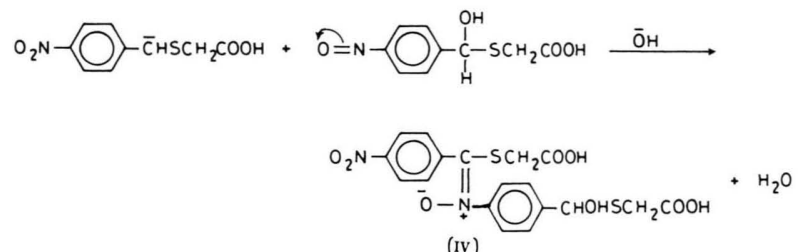

The structure of this nitrone acid was confirmed by estimation of its nitrogen content, molecular weight determination, ${ }^{1} \mathrm{H}-\mathrm{NMR}$, IR and UV spectra. Such a nitrone is unable to react further

[1] P. Buck, Angew. Chem. 81, 136 (1969); Angew. Chem. Int. Ed. Engl. 8, 120 (1969).

[2] H. Zollinger, Azo and Diazo-Chemistry, Chapt. 9, Interscience, New York 1961.

[3] W. H. Perkin, Trans. 37, 546 (1880).

[4] D. Waldrup and B. J. Yager, Texas J. Science 27, 397 (1976). with another molecule of II to give more complex structures, because this nitrone has no longer methylene group. Nitrone is known to be formed by different procedures, among which is the reaction between nitroso compounds and compounds having an active methylene group [11].

No free radicals nor radical anions are involved in the present mechanism since the reaction rate was not changed in the presence of benzoyl peroxide.

The values of the thermodynamic parameters of activation, i.e., the free energies $\Delta G^{\neq}$, the enthalpies $\Delta H^{\neq}$and the entropies $\Delta S^{\neq}$for the two steps are given in Table 3. $\Delta H^{\ddagger}$ and $\Delta S^{\ddagger}$ do not change much as the dioxane content of the solvent mixture is increased, and the compensation effect between $\Delta H^{\ddagger}$ and $T \Delta S^{\mp}$ plays an important role in keeping $\Delta G^{\ddagger}$ more or less constant, in other cases [30, 31]. Moreover the values of the entropy of activation of the second step, $\Delta S_{2}^{ \pm}$, are lower than those for the first step, $\Delta S_{1}^{\neq}$, indicating that the activated complex produced during the elimination of ${ }_{-}^{-} \mathrm{SCH}_{2} \mathrm{COOH}$ from intermediate II is more solvated than that formed from $\mathbf{I}$.

The six 4-nitrobenzyl, aryl sulphides, described in Table 1, were treated with sodium hydroxide in $50 \%$ aqueous dioxan medium. All of them gave $4,4^{\prime}$-diformylazoxybenzene as the main product, which was precipitated from the reaction medium either alone or after dilution. After filteration and acidification of the alkaline filtrate either $4,4^{\prime}$-dicarboxyazoxybenzene or the corresponding azo-acid was precipitated besides a mercaptan which was set free, or its sulphide.

The mechanism presented for the reaction between sodium hydroxide and $\mathbf{I}$, in aqueous dioxane can be applied to the present cases. Thus alkaline aqueous dioxane media change the 4-nitrobenzylthio-system into 4,4'-diformylazoxybenzene and 4,4'-dicarboxyazoxybenzene.

[5] E. B. Reid and E. G. Pritshett, J. Org. Chem. 18, 715 (1953)

[6] V. M. Clark, J. B. Hobbs, and D. W. Hutchinson, Tetrahedron 25, 4241 (1969).

[7] E. H. Huntress and G. L. Foote, J. Amer. Chem. Soc. 64, 1017 (1942).

[8] Y. Iskander and Y. Riad, J. Chem. Soc. 1951, 2054. 
[9] A. Schönberg and Y. Iskander, J. Chem. Soc. 1942, 90.

[10] A. Vogel, Practical Organic Chemistry, 3rd edition, Longmans London 1959, p. 1037.

[11] J. Hamer and A. Macaluso, Chem. Rev. 64, 475 (1964).

[12] W. Kiegel, Tetrahedron Lett. 1969, 223.

[13] T. Kubote, M. Yamakawa, and Y. Mori, Bull. Chem. Soc. Japan 36, 1552 (1963).

[14] E. J. Rubbs and J. A. Villarreal, Tetrahedron Lett. $1969,1841$.

[15] J. B. Lambert, H. F. Shurvell, L. Verbit, R. Cooks, and H. Stout, Organic Structural Analysis, Macmillan Publishing Co. Inc., New York 1976, p. 276.

[16] Y. Riad, A. N. Asaad, G.-A. S. Gohar, and A. A. Abdallah, Z. Naturforsch. 39a, 893 (1984).

[17] J. K. Baxendale and M. A. J. Rodgers, Trans. Faraday Soc. 63, 2004 (1967).

[18] W. R. Waldrin and E. E. Reid, J. Amer. Chem. Soc. 45, 2399 (1923).

[19] R. R. Hudson and G. Klopman, J. Chem. Soc. 1962, 1062.

[20] H. Aptizsch, Chem. Ber. 46, 3098 (1913).
[21] Y. Iskander, Y. Riad, and R. Tewfik, J. Chem. Soc. 1961, 2402.

[22] O. Otto and E. Fischer, Chem. Ber. 28, 1337 (1895).

[23] J. Strakosch, Chem. Ber. 28, 698 (1895).

[24] C. G. Swain, J. Amer. Chem. Soc. 66, 1696 (1944).

[25] A. A. Frost and W. C. Schwemer, J. Amer. Chem. Soc. 74, 1268 (1952); A. A. Frost and R. G. Pearson, Kinetic and Mechanism, John Wiley and Sons, New York 1960.

[26] S. Glasstone, K. L. Laidler, and H. Eyring, The Theory of Rate Processes, McGraw-Hill, New York 1941.

[27] Y. Riad and A. A. Abdallah, Egypt J. Chem. 15, 38 (1972).

[28] G. A. Russel and J. M. Pecororo, J. Amer. Chem. Soc. 101, 3331 (1979).

[29] G. T. Knight and B. Saville, J. Chem. Soc. Perkin Trans. 2, 1973, 1550.

[30] C. D. Richie and W. F. Sager, Prog. Phys. Org. Chem. 2, 323 (1964).

[31] E. Buncel and J. P. Millington, Can. J. Chem. 43, 556 (1965). 